\title{
Impact of Moderate versus Deep Sedation and Trainee Participation on Adenoma Detection Rate - Analysis of a Veteran Population
}

\author{
Hemnishil K. Marella ${ }^{1}$, Nasir Saleem ${ }^{2}$ and Claudio Tombazzi ${ }^{2}$ \\ ${ }^{1}$ Department of Medicine, ${ }^{2}$ Division of Gastroenterology and Hepatology, University of Tennessee Health Science Center, Memphis, TN, \\ USA
}

Background/Aims: The adenoma detection rate (ADR) is used as a quality indicator for screening and surveillance colonoscopy. The study aimed to determine if moderate versus deep sedation affects the outcomes of the ADR and other quality metrics in the veteran population.

Methods: A retrospective review of colonoscopies performed at Memphis Veterans Affairs Medical Center over a one-year period was conducted. A total of 900 colonoscopy reports were reviewed. After exclusion criteria, a total of 229 index, average-risk screening colonoscopies were identified. Data were collected to determine the impact of moderate (benzodiazepine plus opioids) versus deep (propofol) sedation on the ADR, polyp detection rate (PDR), and withdrawal time.

Results: Among 229 screening colonoscopies, 103 (44.9\%) used moderate sedation while 126 (55\%) were done under deep sedation. The ADR and PDR were not significantly different between moderate versus deep sedation at $35.9 \%$ vs. $37.3 \%(p=0.82)$ and $58.2 \%$ vs. 48.4\% ( $p=0.13$ ), respectively. Similarly, there was no significant difference in withdrawal time between moderate and deep sedation (13.4 min vs. $14 \mathrm{~min}, p=0.56$ ) during screening colonoscopies.

Conclusions: In veterans undergoing index, average-risk screening colonoscopies, the quality metrics of the ADR, PDR, and withdrawal time are not influenced by deep sedation compared with moderate sedation. Clin Endosc 2021;54:250-255

Key Words: Adenoma detection rate; Deep sedation; Moderate sedation; Polyp detection rate

\section{INTRODUCTION}

Colorectal cancer (CRC) is the second most common cause of cancer deaths among men and women in the United States. ${ }^{1}$ The estimated lifetime risk of CRC is $5 \% .{ }^{2}$ Among the US veteran population, CRC accounts for about $9 \%$ of all cancers. ${ }^{3}$ Relative to the general population, veterans are older with multiple high-risk comorbidities, impacting CRC risk. ${ }^{3,4}$ In addition, certain lifestyle factors possibly impacting CRC risk in-

Received: April 3, 2020 Revised: June 2, 2020

Accepted: August 26, 2020

Correspondence: Hemnishil K. Marella

Department of Medicine, University of Tennessee Health Science Center, 956 Court Avenue, Suite H314, Memphis, TN 38163, USA

Tel: +1-502-330-8670, Fax: +1-502-330-8670, E-mail: hkmarella@gmail.com

ORCID: https://orcid.org/0000-0001-8901-5900

(cc) This is an Open Access article distributed under the terms of the Creative Commons Attribution Non-Commercial License (http://creativecommons.org/ licenses/by-nc/3.0) which permits unrestricted non-commercial use, distribution, and reproduction in any medium, provided the original work is properly cited. clude a higher smoking prevalence among veterans and poor diet. ${ }^{5,6}$ Since, colonoscopy is a powerful tool in a gastroenterologist's armamentarium, a quality examination is essential to prevent and diagnose CRC. ${ }^{7}$ The detection and removal of adenomatous polyps during colonoscopy have been emphasized significantly to prevent progression to CRC.

According to the American Society for Gastrointestinal Endoscopy (ASGE) and the American College of Gastroenterology (ACG) task force on quality in endoscopy, the adenoma detection rate $(\mathrm{ADR})$ is one of the priority quality metrics for average-risk index screening colonoscopies. ${ }^{8}$ The proposed target ADR is $30 \%$ for men and $20 \%$ for women. ${ }^{8-10}$ Multiple modalities have been studied to improve the ADR and polyp detection rate (PDR), including the quality of bowel preparation, ${ }^{11,12}$ withdrawal time after cecal intubation, ${ }^{13,14}$ sedation versus no sedation, and type of sedation, i.e., moderate sedation using a benzodiazepine and opioid versus deep sedation using propofol. ${ }^{15-19}$ In a study of 52,506 patients undergoing screening colonoscopies, there was no difference in the ADR 
and PDR when patients who received sedation versus those without sedation were compared; however, sedation led to a higher cecal intubation rate (CIR). ${ }^{20}$ There are conflicting prior reports on the effects on the ADR and PDR by moderate sedation compared with deep sedation. ${ }^{15-21}$ We aimed to study the impact of moderate and deep sedation on the ADR, PDR, and withdrawal time in average-risk, screening and non-screening colonoscopies in a veteran population. We also aimed to study the impact of the type of trainee participation on these parameters.

\section{MATERIALS AND METHODS}

A retrospective review of all colonoscopies performed at Memphis Veterans Affairs (VA) Medical Center, Memphis, TN, USA, during a 12-month period, between October 2018 and September 2019, was conducted. As shown in Fig. 1, a total of 900 colonoscopy reports were identified. After excluding high-risk patients (i.e., those with a family history of colon cancer or genetic syndromes), surveillance examinations for colon polyps, diagnostic examinations for the evaluation of gastrointestinal symptoms, and patients who had undergone prior colon resection, a total of 229 index, average-risk screening colonoscopy reports were identified. The colonoscopies were performed with or without the participation of a gastroenterology (GI) fellow under the supervision of an attending physician. Moderate sedation was administered by the trained nursing staff under the supervision of an attending physician, while deep sedation was administered by an anesthesiologist

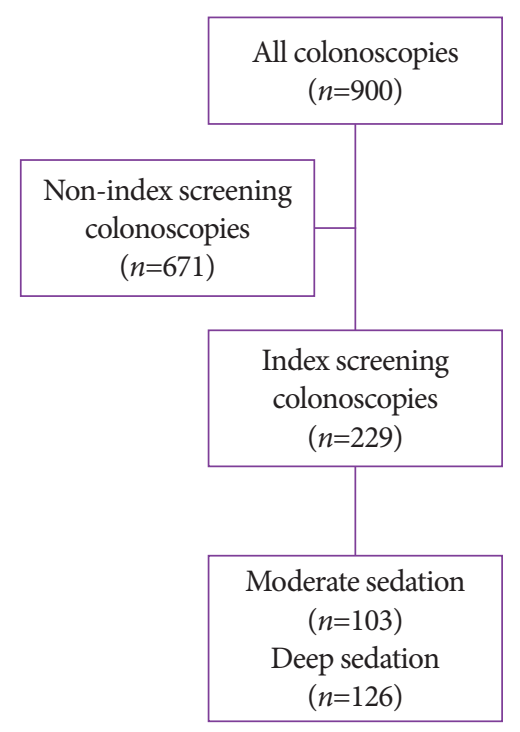

Fig. 1. Flow chart of the patient population. or a certified nurse anesthetist supervised by an anesthesiologist. Moderate sedation included benzodiazepine plus opioids (i.e., midazolam and fentanyl), while deep sedation included propofol. All patients were evaluated to assess their risk for sedation prior to the procedure. An American Society of Anesthesiologists (ASA) class associated with a risk of adverse events during GI procedures was determined for each patient. ${ }^{22}$ The patients in ASA class I, II, or III were administered moderate sedation. In the presence of an anesthesia provider, deep sedation (propofol-based sedation) was administered for patients in ASA class I, II, or III for additional comfort, patient safety, procedural efficiency, or an anticipated intolerance to the moderate sedation. Deep sedation was also directed to patients with an increased risk of adverse events due to comorbidities (ASA class IV). The age, gender, body mass index (BMI), ASA class, type of sedation used, quality of bowel preparation, and number and pathology of polyps were recorded from review of patient charts.

Prior publications have addressed the impact of trainee participation on quality metrics in colonoscopies. ${ }^{23-28}$ As the colonoscopies in our study population were performed at a training center for the GI fellowship program at the University of Tennessee Health Science Center, the impact of trainee participation on the ADR, PDR, and procedure times was analyzed.

Data were analyzed to determine the impact of moderate versus deep sedation on the ADR, PDR, and withdrawal time. In a separate analysis, we also analyzed all 900 colonoscopies, including non-screening examinations, to assess the impact of the type of sedation on the aforementioned parameters. Statistical analysis was performed using Stata 15.1 (StataCorp LLC, College Station, TX, USA). Using descriptive statistics, a two-tailed unpaired $t$-test was used for continuous data, while the chi-squared test was used for categorical data. A $p$-value of $<0.05$ was considered statistically significant. This study was approved by the Institutional Review Board of the VA Medical Center.

\section{RESULTS}

A total of 229 index, average-risk screening colonoscopies were identified, with 103 (44.9\%) patients receiving moderate sedation and 126 (55\%) receiving deep sedation. As shown in Table 1, the overall mean age of patients undergoing index screening colonoscopies was $58.6 \pm 7.3$ years, and the mean BMI was $30.6 \pm 7.2 \mathrm{~kg} / \mathrm{m}^{2}$. Patients who received deep sedation had a higher BMI than the moderate sedation group $\left(32.6 \pm 8.1 \mathrm{~kg} / \mathrm{m}^{2}\right.$ vs. $\left.28.0 \pm 4.8 \mathrm{~kg} / \mathrm{m}^{2}, p<0.00\right)$. Since this study 
was conducted in a veteran population, the patients were predominantly male (89.5\%). Patients with a higher ASA class were more likely to get deep sedation than moderate sedation ( $2.8 \pm 0.41$ vs. $2.68 \pm 0.49, p<0.0083)$. As shown in Fig. 2 , the overall ADR was $36.6 \%$ and PDR was $52.8 \%$ in the index colonoscopy group. The ADR and PDR were not significantly different between the moderate and deep sedation groups ( $35.9 \%$ vs. $37.3 \%, p=0.82$ and $58.2 \%$ vs. $48.4 \%, p=0.13$, respectively). There was no significant difference in withdrawal time between moderate and deep sedation (13.4 min vs. 14 $\min , p=0.56$ ) during screening colonoscopies.

Similarly, as shown in Table 2, when all 900 colonoscopies were analyzed, there was no significant difference in the ADR and PDR between the moderate and deep sedation groups ( $45.8 \%$ vs. $50.2 \%, p=0.18$ and $60.2 \%$ vs. $59.6 \%, p=0.89$, respectively). In addition, there was no significant difference in withdrawal time between the two groups (16.3 min vs. 15.0 min, $p=0.09$ ). Patients who received deep sedation had a higher BMI than the moderate sedation group $(31.5 \pm 7.1 \mathrm{~kg} /$ $\mathrm{m}^{2}$ vs. $27.9 \pm 4.8 \mathrm{~kg} / \mathrm{m}^{2}, p<0.00$ ), and similarly, patients with a higher ASA class were more likely to get deep sedation than moderate sedation $(2.9 \pm 0.37$ vs. $2.7 \pm 0.49, p<0.000)$.

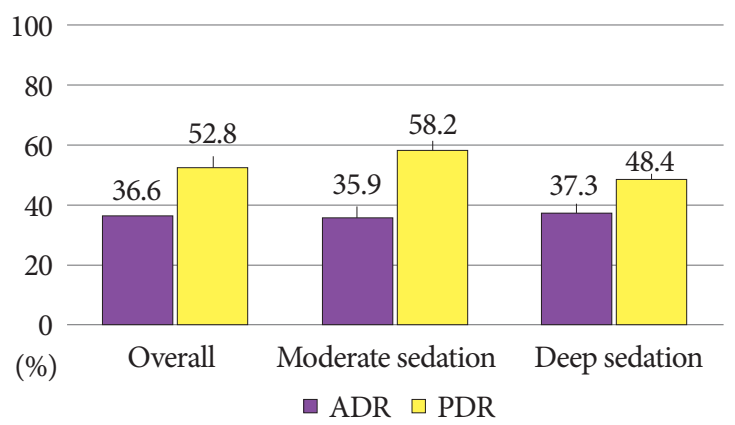

Fig. 2. Adenoma detection rate (ADR) and polyp detection rate (PDR) for moderate and deep sedation.

Table 1. Demographics of Patients Undergoing Index Average-Risk Screening Colonoscopy

\begin{tabular}{|c|c|c|c|c|}
\hline Parameter & Overall $(n=229)$ & Moderate sedation $(n=103)$ & Deep sedation $(n=126)$ & $p$-value \\
\hline Age, yr, mean \pm SD & $58.6 \pm 7.3$ & $59.6 \pm 7.4$ & $57.7 \pm 7.1$ & $0.05^{\mathrm{a})}$ \\
\hline $\mathrm{BMI}, \mathrm{kg} / \mathrm{m}^{2}$, mean $\pm \mathrm{SD}$ & $30.6 \pm 7.2$ & $28.0 \pm 4.8$ & $32.6 \pm 8.1$ & $0.00^{\mathrm{a})}$ \\
\hline Males, $n(\%)$ & $205(89.5 \%)$ & $93(90.2 \%)$ & $112(88.8 \%)$ & $0.730^{\mathrm{b})}$ \\
\hline Good bowel preparation, $n(\%)$ & $208(91 \%)$ & $96(93.2 \%)$ & $112(88.8 \%)$ & $0.42^{\mathrm{b})}$ \\
\hline Adenoma detection rate (\%) & $84 / 229(36.6 \%)$ & $37 / 103(35.9 \%)$ & $47 / 126(37.3 \%)$ & $0.829^{\mathrm{b})}$ \\
\hline Polyp detection rate (\%) & $121 / 229(52.8 \%)$ & $60 / 103(58.2 \%)$ & $61 / 126(48.4 \%)$ & $0.138^{\mathrm{b})}$ \\
\hline Withdrawal time ${ }^{c)}$, minutes $\pm S D$ & $13.7 \pm 6.7$ & $13.4 \pm 6.4$ & $14.0 \pm 7.0$ & $0.56^{\mathrm{a})}$ \\
\hline ASA class & $2.7 \pm 0.45$ & $2.68 \pm 0.49$ & $2.8 \pm 0.41$ & $0.0083^{\mathrm{a}}$ \\
\hline
\end{tabular}

ASA, American Society of Anesthesiologists; BMI, body mass index; SD, standard deviation.

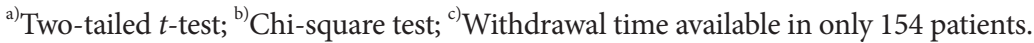

Table 2. Demographics of All Patients in the Cohort Undergoing Colonoscopy for All-Indications

\begin{tabular}{lcccc}
\hline Parameter & Overall $(\boldsymbol{n = 9 0 0})$ & Moderate sedation $(\boldsymbol{n = 3 7 7})$ & Deep sedation $(\boldsymbol{n}=\mathbf{5 2 3})$ & $\boldsymbol{p}$-value \\
\hline Age, $\mathrm{yr}, \mathrm{mean} \pm \mathrm{SD}$ & $63.6 \pm 8.7$ & $64.6 \pm 8.4$ & $62.9 \pm 8.9$ & $0.005^{\mathrm{a})}$ \\
$\mathrm{BMI}, \mathrm{kg} / \mathrm{m}^{2}$, mean $\pm \mathrm{SD}$ & $30.0 \pm 6.55$ & $27.9 \pm 4.8$ & $31.5 \pm 7.1$ & $0.000^{\mathrm{a})}$ \\
Males, $n(\%)$ & $830(92.2 \%)$ & $350(92.8 \%)$ & $480(91.7 \%)$ & $0.558^{\mathrm{b})}$ \\
Good bowel preparation, $n(\%)$ & $776(86.2 \%)$ & $349(92.5 \%)$ & $427(81.6 \%)$ & $0.00^{\mathrm{b})}$ \\
Polyp detection rate $(\%)$ & $539 / 900(59.8 \%)$ & $227 / 377(60.2 \%)$ & $312 / 523(59.6 \%)$ & $0.894^{\mathrm{b})}$ \\
Adenoma detection rate $(\%)$ & $436 / 900(48.5 \%)$ & $173 / 377(45.8 \%)$ & $263 / 523(50.2 \%)$ & $0.183^{\mathrm{b})}$ \\
Withdrawal time ${ }^{\mathrm{c}}$, minutes \pm SD & $15.5 \pm 9.5$ & $16.3 \pm 10.2$ & $15.0 \pm 8.9$ & $0.09^{\mathrm{a})}$ \\
ASA score & $2.8 \pm 0.44$ & $2.7 \pm 0.49$ & $2.9 \pm 0.37$ & $0.000^{\mathrm{a})}$ \\
\hline
\end{tabular}

ASA, American Society of Anesthesiologists; BMI, body mass index; SD, standard deviation.

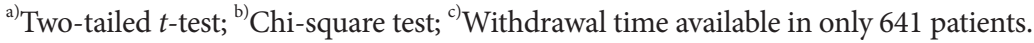


Table 3. Index Average-Risk Screening Colonoscopy with/without Gastroenterology Fellow

\begin{tabular}{|c|c|c|c|c|}
\hline Parameter & Overall $(n=229)$ & Attending alone $(n=68)$ & Attending and fellow $(n=161)$ & $p$-value \\
\hline Age, yr, mean \pm SD & $58.6 \pm 7.3$ & $59.5 \pm 7.1$ & $58.6 \pm 7.4$ & $0.88^{\mathrm{a})}$ \\
\hline $\mathrm{BMI}, \mathrm{kg} / \mathrm{m}^{2}$, mean $\pm \mathrm{SD}$ & $30.6 \pm 7.2$ & $31.8 \pm 8.1$ & $30.1 \pm 6.7$ & $0.08^{\mathrm{a})}$ \\
\hline Males, $n(\%)$ & $205(89.5 \%)$ & $62(91 \%)$ & $143(89 \%)$ & $0.595^{\mathrm{b})}$ \\
\hline Good bowel preparation, $n(\%)$ & $208(91 \%)$ & $62(91 \%)$ & $146(91 \%)$ & $0.809^{\mathrm{b})}$ \\
\hline Polyp detection rate (\%) & $121 / 229(52.8 \%)$ & $30 / 68(44.1 \%)$ & $91 / 161(56.5 \%)$ & $0.086^{\mathrm{b})}$ \\
\hline Adenoma detection rate $(\%)$ & $84 / 229(36.6 \%)$ & $20 / 68(29.4 \%)$ & $64 / 161(39.7 \%)$ & $0.138^{\mathrm{b})}$ \\
\hline Cecal intubation time ${ }^{c)}$, minutes $\pm S D$ & $8.31 \pm 5.6$ & $7.09 \pm 4.71$ & $8.76 \pm 5.92$ & $0.102^{\mathrm{a})}$ \\
\hline Withdrawal time ${ }^{c)}$, minutes $\pm S D$ & $13.7 \pm 6.7$ & $11.11 \pm 5.9$ & $14.7 \pm 6.8$ & $0.003^{\mathrm{a})}$ \\
\hline Total procedure time ${ }^{c)}$, minutes $\pm S D$ & $22.7 \pm 11.0$ & $19.1 \pm 10.4$ & $24.1 \pm 11.0$ & $0.006^{\mathrm{a})}$ \\
\hline Deep sedation, $n(\%)$ & $126(55 \%)$ & $44(64.7 \%)$ & $82(50.9 \%)$ & $0.056^{\mathrm{b})}$ \\
\hline ASA class & $2.7 \pm 0.45$ & $2.7 \pm 0.44$ & $2.7 \pm 0.46$ & $0.668^{\mathrm{a})}$ \\
\hline
\end{tabular}

ASA, American Society of Anesthesiologists; BMI, body mass index; SD, standard deviation.

a) Two-tailed $t$-test; ${ }^{\text {b) }}$ Chi-square test; ${ }^{\text {c) }}$ Cecal intubation time available in 156 patients, withdrawal time available in 154 patients, total procedure time available 175 patients.

As shown in Table 3, in the total of 229 index screening colonoscopies, 68 (29.6\%) were performed by an attending physician alone, and 161 (70.3\%) were performed by a GI fellow supervised by one of the same six GI attending physicians. The ADR was $29.4 \%$ when the procedure was performed by a GI attending physician alone, while it increased to $39.7 \%$ with GI fellow participation, although this difference was not statistically significant $(p=0.13)$. Similarly, the PDR with GI fellow participation was $56.5 \%$ compared with $44.1 \%$ for GI attending physician alone $(p=0.086)$. The cecal intubation time, withdrawal time, and total procedure time were longer when a fellow was involved.

\section{DISCUSSION}

CRC is the second leading cause of cancer-related death, and monitoring quality metrics for screening colonoscopy is essential to reduce morbidity and mortality. ${ }^{1-4}$ This is the first study, to the best of our knowledge, to evaluate the effect of moderate sedation compared with deep sedation on the ADR and PDR in the veteran population. Our results indicate that in veterans undergoing index screening colonoscopies, the quality metrics of the ADR, PDR, and withdrawal time are not influenced by deep sedation compared with moderate sedation. Similarly, adenoma and PDRs in non-screening colonoscopies are similar between the two groups. In addition, trainee participation led to a trend towards increased adenoma detection in colonoscopies, although this was not statistically significant.

Previous studies have evaluated the effect of sedation on several quality metrics such as the ADR, PDR, and CIR. ${ }^{15-21}$ Initially, Bannert et al. ${ }^{20}$ showed sedation not influencing the ADR and PDR; however, leading to a higher CIR. Radaelli et al. performed a study using the survey of the Italian Association of Hospital Gastroenterologists, evaluating all colonoscopies done at 278 endoscopy centers in a two-week period and showed that moderate versus deep sedation did not affect the ADR and PDR. ${ }^{17}$ In their study population, screening colonoscopies constituted $13 \%$ of all total colonoscopies performed with $3.1 \%$ of the patients receiving propofol. ${ }^{17}$ Due to the distribution of patients receiving moderate versus deep sedation, it is inadequate to draw conclusions regarding the effects of sedation on colonoscopy quality metrics. The studies done by Metwally et al. ${ }^{15}$ and Nakshabendi et al. ${ }^{16}$ demonstrated that moderate sedation compared with deep sedation had no significant effect on the ADR and PDR. In contrast, Wang et al. studied the effect of sedation, in all screening and surveillance colonoscopies, identifying "advanced lesions" as $>9 \mathrm{~mm}$ or a suspected malignant tumor. ${ }^{21}$ It was concluded that moderate sedation contributed to a higher PDR, and deep sedation contributed to the identification of "advanced lesions". Thirumurthi et al. showed that the ADR is higher with deep sedation than with moderate sedation ( $46.3 \%$ vs. $41.2 \%, p=0.01){ }^{18}$ This study included colonoscopies of non-gastrointestinal cancers, and a specific criterion was used to eliminate patients 
from getting moderate sedation (i.e., patient with comorbid conditions). These potential confounding variables could have influenced the results of their study. Finally, Turse et al. performed a retrospective study at an outpatient endoscopy center, including 585 average-risk patients. ${ }^{19}$ The study concluded that the ADR and PDR were not significantly affected by moderate sedation compared with deep sedation. ${ }^{19}$ The PDR was slightly higher in the moderate sedation group despite the lack of significance, similar to the findings in our study. Our study further validates these findings providing data from a veteran population. The lack of statistical significance, between these two groups, could be secondary to the procedural technique similar for each senior endoscopist despite the level of sedation of the patient. Daily patient volume was the same for each endoscopist. The factors possibly influencing the ADR and PDR, such as the quality of the bowel preparation and the withdrawal times, were similar between the groups.

Prior studies have shown conflicting results on the impact of trainee participation on quality metrics in colonoscopies. ${ }^{23-28}$ Studies done by Rogart et al., Peters et al., and Qayed et al. demonstrated that fellow participation leads to a higher ADR compared to procedures done by an attending physician alone. ${ }^{24,26,28}$ In contrast, Bitar et al. demonstrated fellow participation having no impact on the ADR. ${ }^{27}$ Similarly, Buchner et al. showed that there was a trend toward increased adenoma detection when a fellow was present; however, these findings were not statistically significant ( $30 \%$ vs. $26 \%, p=0.11$ ). ${ }^{25}$ The findings of Buchner et al. are similar to the findings in our study, which showed a trend toward an increased adenoma detection in colonoscopies with the presence of a fellow compared with the attending physician alone (39.7 vs. 29.4, $p=0.138){ }^{25}$ The withdrawal time is an important factor for improving the $\mathrm{ADR}^{25}$ In this cohort, the procedure time and withdrawal time were significantly higher with the involvement of a GI fellow. Fellows in training tend to have a higher procedural time than that of attending physician(s), as they are learning the technique and enhancing their detection of polyps and adenomas. This is consistent with the previous study, which showed the involvement of a GI fellow leading to prolonged procedure times; however, improvement was noted as the fellow progressed through training. ${ }^{29}$ In our study, despite the lack of significance in the ADR and PDR with the addition of a GI fellow, there was a trend toward higher values. Presence of an additional observer could lead to an increased detection of polyps. Previous studies have shown having a nurse observer leading to a higher polyp and adenoma detection during colonoscopy ${ }^{30-32}$ Similarly, the presence of a GI fellow can lead to an improved polyp detection and ADR.

The strength of our study includes having patients with comparable demographics in the moderate and deep sedation groups, undergoing index, average-risk screening colonoscopy. Potential limitations of our study include a retrospective analysis and inclusion of patients from a single center. However, prior studies on this topic have also been retrospective. Also, since our study population predominantly comprised men, it is difficult to draw a conclusion based on our results in women.

In conclusion, our study did not find a difference in the ADR and PDR when using deep sedation compared with moderate sedation in a veteran population. However, further randomized control trials are needed to validate these results.

\section{Conflicts of Interest}

The authors have no potential conflicts of interest.

Funding

None.

Author Contributions

Conceptualization: Hemnishil K. Marella, Nasir Saleem, Claudio Tombazzi Data curation: HKM, NS, CT

Formal analysis: HKM, NS, CT

Writing-original draft: HKM, NS, CT

Writing-review\&editing: HKM, NS, CT

ORCID
Hemnishil K. Marella:

Nasir Saleem:

Claudio Tombazzi: https://orcid.org/0000-0001-8901-5900 https://orcid.org/0000-0001-6831-2674 https://orcid.org/0000-0002-9322-6484

\section{REFERENCES}

1. Siegel RL, Miller KD, Jemal A. Cancer statistics, 2020. CA Cancer J Clin 2020;70:7-30.

2. Zauber AG, Winawer SJ, O’Brien MJ, et al. Colonoscopic polypectomy and long-term prevention of colorectal-cancer deaths. N Engl J Med 2012;366:687-696.

3. Zullig LL, Williams CD, Fortune-Britt AG. Lung and colorectal cancer treatment and outcomes in the Veterans Affairs health care system. Cancer Manag Res 2015;7:19-35.

4. Agha Z, Lofgren RP, VanRuiswyk JV, Layde PM. Are patients at Veterans Affairs medical centers sicker? A comparative analysis of health status and medical resource use. Arch Intern Med 2000;160:3252-3257.

5. Brown DW. Smoking prevalence among US veterans. J Gen Intern Med 2010;25:147-149.

6. Park SY, Zhu K, Potter JF, Kolonel LN. Health-related characteristics and dietary intakes of male veterans and non-veterans in the multiethnic cohort study (United States). J Mil Veterans Health 2011;19:4-9.

7. US Preventive Services Task Force; Bibbins-Domingo K, Grossman DC, et al. Screening for colorectal cancer: US preventive services task force recommendation statement. JAMA 2016;315:2564-2575.

8. Rex DK, Schoenfeld PS, Cohen J, et al. Quality indicators for colonoscopy. Gastrointest Endosc 2015;81:31-53.

9. Atia MA, Patel NC, Ratuapli SK, et al. Nonneoplastic polypectomy during screening colonoscopy: the impact on polyp detection rate, ade- 
noma detection rate, and overall cost. Gastrointest Endosc 2015;82:370375.e1.

10. Rex DK, Petrini JL, Baron TH, et al. Quality indicators for colonoscopy. Am J Gastroenterol 2006;101:873-885.

11. Kilgore TW, Abdinoor AA, Szary NM, et al. Bowel preparation with split-dose polyethylene glycol before colonoscopy: a meta-analysis of randomized controlled trials. Gastrointest Endosc 2011;73:1240-1245.

12. Radaelli F, Paggi S, Hassan C, et al. Split-dose preparation for colonoscopy increases adenoma detection rate: a randomised controlled trial in an organised screening programme. Gut 2017;66:270-277.

13. Jung Y, Joo YE, Kim HG, et al. Relationship between the endoscopic withdrawal time and adenoma/polyp detection rate in individual colonic segments: a KASID multicenter study. Gastrointest Endosc 2019;89:523530 .

14. Patel VD, Thompson WK, Lapin BR, Goldstein JL, Yen EF. Screening colonoscopy withdrawal time threshold for adequate proximal serrated polyp detection rate. Dig Dis Sci 2018;63:3084-3090.

15. Metwally M, Agresti N, Hale WB, et al. Conscious or unconscious: the impact of sedation choice on colon adenoma detection. World J Gastroenterol 2011;17:3912-3915.

16. Nakshabendi R, Berry AC, Munoz JC, John BK. Choice of sedation and its impact on adenoma detection rate in screening colonoscopies. Ann Gastroenterol 2016;29:50-55

17. Radaelli F, Meucci G, Sgroi G, Minoli G. Technical performance of colonoscopy: the key role of sedation/analgesia and other quality indicators. Am J Gastroenterol 2008;103:1122-1130.

18. Thirumurthi S, Raju GS, Pande M, et al. Does deep sedation with propofol affect adenoma detection rates in average risk screening colonoscopy exams? World J Gastrointest Endosc 2017;9:177-182.

19. Turse EP, Dailey FE, Bechtold ML. Impact of moderate versus deep sedation on adenoma detection rate in index average-risk screening colonoscopies. Gastrointest Endosc 2019;90:502-505.

20. Bannert C, Reinhart K, Dunkler D, et al. Sedation in screening colonoscopy: impact on quality indicators and complications. Am J Gastroenterol 2012;107:1837-1848.

21. Wang A, Hoda KM, Holub JL, Eisen GM. Does level of sedation impact detection of advanced neoplasia? Dig Dis Sci 2010;55:2337-2343.

22. Enestvedt BK, Eisen GM, Holub J, Lieberman DA. Is the American Society of Anesthesiologists classification useful in risk stratification for endoscopic procedures? Gastrointest Endosc 2013;77:464-471.

23. El-Halabi MM, Barrett PR, Martinez Mateo M, Fayad NF. Should we measure adenoma detection rate for gastroenterology fellows in training? Gastroenterology Res 2018;11:290-294.

24. Rogart JN, Siddiqui UD, Jamidar PA, Aslanian HR. Fellow involvement may increase adenoma detection rates during colonoscopy. Am J Gastroenterol 2008;103:2841-2846.

25. Buchner AM, Shahid MW, Heckman MG, et al. Trainee participation is associated with increased small adenoma detection. Gastrointest Endosc 2011;73:1223-1231.

26. Peters SL, Hasan AG, Jacobson NB, Austin GL. Level of fellowship training increases adenoma detection rates. Clin Gastroenterol Hepatol 2010;8:439-442.

27. Bitar H, Zia H, Bashir M, et al. Impact of fellowship training level on colonoscopy quality and efficiency metrics. Gastrointest Endosc 2018;88:378-387.

28. Qayed E, Shea L, Goebel S, Bostick RM. Association of trainee participation with adenoma and polyp detection rates. World J Gastrointest Endosc 2017;9:204-210.

29. McCashland T, Brand R, Lyden E, de Garmo P. The time and financial impact of training fellows in endoscopy. CORI research project. Clinical outcomes research initiative. Am J Gastroenterol 2000;95:3129-3132.

30. Aslanian HR, Shieh FK, Chan FW, et al. Nurse observation during colonoscopy increases polyp detection: a randomized prospective study. Am J Gastroenterol 2013;108:166-172.

31. Kim TS, Park DI, Lee DY, et al. Endoscopy nurse participation may increase the polyp detection rate by second-year fellows during screening colonoscopies. Gut Liver 2012;6:344-348.

32. Lee CK, Park DI, Lee SH, et al. Participation by experienced endoscopy nurses increases the detection rate of colon polyps during a screening colonoscopy: a multicenter, prospective, randomized study. Gastrointest Endosc 2011;74:1094-1102. 